\title{
A CONJUNTURA NACIONAL E A SITUAÇAO DO ENFERMEIRO *
}

\section{Graciette Borges da Silva**}

SILVA, G.B. da A conjuntura nacional e a situação do enfermeiro. Rev. Esc. Enf. USP, São Paulo, 20(3):237-241, 1986.

Este artigo apresenta algumas colocaçōes preliminares sobre a enfermagem brasileira e busca apreender a articulação desta prática social com uma estrutura $e$ conjuntura especificas. A seguir, reverte o faco da andilise para o interior da enfermagem, identificando a heterogeneidade que a caracteriza, apontando as suas contradições e finaliza a discussão com a questão referente ao processo de sindicalização na área.

Inicialmente, quero cumprimentar os organizadores do II Encontro de Entidades Sindicais e Pré Sindicais de Enfermeiros pela realização deste evento e agradecer o convite que me foi feito. Faço questão de tornar enfáticos estes cumprimentos, pois imagino os esforços dispendidos e o trabalho ingente envolvido na realização deste Encontro; ele era imprescindivel para a troca de informaçōes e experiências relacionadas ao objetivo da criação de sindicatos em vários Estados do Brasil e do fortalecimento dos poucos já existentes. O objetivo, uma vez atingido, significará o término de uma batalha e o inicio de outras, onde problemas de natureza diferente constituirão novos desafios a serem enfrentados por ora, entretanto, o problema é transpor os obstáculos internos e externos envolvidos no processo de sindicalização de categoria dos enfermeiros. Os obstáculos internos derivam, suponho, de acomodação, inércia, intransigência de opiniões, posições cristalizadas, enfim, incompreensões de variados matizes. Os obstáculos externos decorrem da série de exigências legais (embora ilegitimas) feitas pelo governo, desde os idos de 1930, para a constituição de sindicatos em nosso pais, onde o sindicalismo apresenta-se atrelado ao Estado, fomentando o peleguismo. Entretanto, estou convencida de que o novo sindicalismo brasileiro em gestação desde o final da década de 1960, está forjando lideranças autênticas, que contribuirão decisivamente para a emancipação das classes trabalhadoras, não se comportando, portanto, como muitos dos seus antecessores que, no dizer mordaz de Maurício Tragtenberg, ao se arvorarem em emancipadores de sua classe social, dela se emanciparam.

Pretendo apresentar aqui, primeiramente, algumas colocações ligadas ao tema "A enfermagem na conjuntura atual da sociedade brasileira",

\footnotetext{
- Comunicaço apresentada no II Encontro de Entidades sindicais a Pré-Sindicais de Intermelros, realizado em Belo Horizonte, M.G., de 21 a 23 de abril de 1983.

* Professor Assigtente de Soclologia da Bscola de Fnfermagem de Ribeirøo Preto-USP.
} 
refletindo "en passant" sobre como se dá a articulação dessa prática social no contexto da formação social de um país capitalista sub-desenvolvido e, em segundo lugar, tentar a análise interna da enfermagem brasileira na atualidade, buscando apreender sua especificidade. Isto significa partir do duplo pressuposto de que se de um lado não se pode entender a enfermagem isoladamente do contexto sócio-econômico-politico onde se insere, de outro, tal assertiva não significa transformá-la em mero epifenômeno do referido contexto.

No que se refere à primeira temática (enfermagem e conjuntura), penso ser importante destacar os pontos que seguem:

ESTRUTURALMENTE, a sociedade brasileira é definida pelos autores Marxistas, como uma formação social capitalista subdesenvolvida que, durante este século, do ponto de vista da política econômica, centrou-se basicamente em torno de dois modelos: o denominado "nacional desenvolvimentismo" e o denominado "capitalismo associado". O primeiro, abrangendo o periodo que se estende de 1930 a meados dos anos cinqüenta, caracterizado fundamentalmente pelo processo de substituição de importações; sobreveio à derrocada do modelo primário-exportador tradicional, que vigorou até a Revolução de 1930, e envolve várias fases, segundo TAVARES ${ }^{2}$ a saber:

a) a implantação, na década de 30 , de indústrias de bens não duráveis de consumo final (alimentícias, de bebidas, de móveis, têxtil), que utilizar tecnologia simples, absorvedora de mão-de-obra;

b) a implantação da indústria pesada, na década de 1940, cujo símbolo maior é a Usina de Volta Redonda;

c) a implantação, na década de 50 , da indústria de bens de consumo duráveis como as de eletrodomésticos, a automobilística, a de construção naval etc.

No decorrer da segunda metade da década de 1950, emergiu um novo modelo de política econômica, dubiamente denominado "capitalismo associado", (onde o adjetivo "associado" supõe relações simétricas, encobrindo a assimetria de fato existente). Este modelo envolveu aumento considerável da intervenção do governo na economia (iniciada em 1930) e a opção pela entrada maciça de capital estrangeiro na economia brasileira para financiar grande parte dos investimentos nos setores acima referidos, opção esta que significou o escancaramento gradativo de nossas portas à exploração das empresas multinacionais. Suas características principais são: o extraordinário processo de modernização por que passou a sociedade brasileira a partir sobretudo dos anos 60 (não confundir com desenvolvimento), cujos indicadores mais evidentes são dados pela sofisticação tecnológica, exemplificadas pelo avanço das telecomunicações e por obras gigantescas de engenharia como Itaipu etc., tecnologia de capital intensivo, isto é, poupadora de mão-de-obra, num país onde existe abundância de mão-de-obra. A face negativa desta modernização tem por caracteres centrais a concentração iníqüa da renda e seus corolários: 
o aumento das populações faveladas nas grandes cidades, a desnutrição em graus diversos, 0 aumento da delinqüência das camadas desfavorecidas. . .

Quanto à caracterização da área da saúde-doença em tal contexto, resumidamente falando, os seguintes pontos precisam ser destacados: o custo crescente de assistência médica a partir dos anos 50 (a tecnificação do ato médico, o desenvolvimento da indústria farmacêutica e de equipamentos); o fenômeno da medicalização da sociedade; a privatização também crescente desta assistência, no Brasil, sobretudo a partir de meados da década de 60 .

Em suma, tal panorama evidencia a existência de um tipo de medicina do capital e de enfermagem do capital, isto é, de uma política governamental de saúde voltada para servir aos interesses da acumulação de capital (gerada no setor da produção de bens e serviços da área, o complexo médico - industrial); estes interesses são traduziveis no favorecimento de uma minoria da população através da destinação de polpudas verbas para a aquisição de equipamentos sofisticadissimos, que realiza a mais - valia gerada naquele setor; em parcas verbas para a prevenção de doenças perfeitamente controláveis e evitáveis; no uso e abuso de paliativos como a distribuição de merenda escolar, de leite em pó, de alimentos para nutrizes e gestantes, o que favorece, mais uma vez, os interesses econômicos de multinacionais.

CONJUNTURALMENTE, o quadro atual da sociedade brasileira caracteriza-se, como é por demais sabido, pelo agravamento da dívida externa, por uma distribuição injusta da renda, pelo aumento do desemprego, pelo aviltamento dos salários, por uma inflação desenfreada, que agravam os fatores anteriormente mencionados que são conseqüências do tipo de estrutura sócio-econômica dominante. Nesta conjuntura econômica, na medida em que a enfermagem se caracteriza pelo assalariamento, o desemprego também constitui problema, assim como a perda do poder aquisitivo dos salários de suas várias categorias. Dentro da lógica do sistema capitalista de diminuir custos para aumentar os lucros, tem ocorrido, por exemplo, com freqüência cada vez maior, a admissão de enfermeiras, em hospitais particulares com salário de auxiliar de enfermagem.

A conjuntura política, por sua vez, tem-se caracterizado pelo apregoamento estridente da abertura democrática como sendo uma dádiva governamental quando, na realidade, foi uma árdua conquista do povo brasileiro, uma conquista parcial, embora, que deixa muito a desejar ainda, visto que coexiste com instrumentos bastante autoritários e ameaçadores como a Lei de Segurança Nacional e a lei de greve.

No que se refere, finalmente, à tentativa de uma análise a partir do interior da prática social da enfermagem, acho importante enfatizar o seguinte aspecto: a existência de um discurso acadêmico (materializado em teses, anais, artigos em revistas especializadas) de caráter nitidamente ideológico, ou seja, escamoteador da realidade desta prática 
social, que esconde, ou melho, não se dá conta das contradições existentes no interior da enfermagem.

Para exemplificar algumas das contradições aí existentes, lembramos:

a) a contradição entre o conteúdo do discurso ético-filosófico dominante no ensino de enfermagem e a sua prática. Nas escolas de enfermagem o cuidado direto ao paciente é enaltecido como o objeto da prática da categoria das enfermeiras, como também das demais categorias. Em sua atividade profissional, contudo, isso não constitui regra mas exceção. Pergunto: muda-se o objeto, reformula-se-o ou muda-se a prática?

b) E dada grande ênfase à concepção globalizadora do corpo humano (doente), apresentando-o como um todo bio-psico-social, o que é louvável. Concretamente, entretanto, dentro das atuais condiçōes dominantes no setor saúde, aquela totalidade é fragmentada sob vários aspectos. Ocorre uma fragmentação do paciente para atender não só às diversas especialidades médicas mas também às diversas categorias profissionais da saúde. Há uma "fragmentação do processo da doença, consubstanciada no corte entre ações terapêuticas e preventivas"1... Há ainda fragmentação do processo de atendimento ao doente que, nas várias fases da atenção ambulatorial (pré-consulta, consulta e pós-consulta) é alvo de uma série de perguntas e informações superpostas, por parte de diferentes categorias de profissionais de saúde. Por sua vez, a referida totalidade bio-psico-social é ensinada como constituindo uma totalidade indiferenciada. Isto significa ignorar as vinculações de classe social dos pacientes, aspecto este central dentro de uma abordagem critica ${ }^{1}$.

c) A prática social da enfermagem, como é sabido, apresenta composição interna e externa heterogênea. A heterogeneidade de sua composição interna refere-se à existência das várias categorias que a constituem. A heterogeneidade de sua composição externa refere-se às diferentes alternativas institucionais de inserção de seus membros no mercado de trabalho (instituições públicas, privadas etc).

Acho importante chamar a atenção para o fato de que a mencionada heterogenidade interna, é freqüentemente esquecida, o que gera ambigüidade muito grande, que contribui enormemente para a perpetuação da situação de crise vivida pela categoria das enfermeiras atualmente e que está ligada a um de seus problemas centrais: o da indefinição de seu status-papel (fruto das contradições não percebidas e reprodutora delas).

Quais são indicadores desta ambigüidade? A predominância (quase que exclusividade) de colocações extremamente genéricas que se reportam à enfermagem como se esta constituísse um todo homogêneo, colocações estas, por exemplo, que se refere a "problemas da enfermagem", quando se trata de problemas específicos das enfermeiras. Tal aspecto liga-se diretamente à questão do processo de sindicalização na área. Pergunto: nas atuais circunstâncias sócio-político-econômicas da sociedade brasileira (também bastante heterogênea) que via é mais pertinente, 
a da constituição de sindicatos de enfermeiros, ou de enfermagem ou mesmo de profissionais da saúde? Estou informada de que esta questão jå foi bastante discutida. Nas atuais circunstâncias, parece-me, a única via possível é a que o movimento de sindicalização tem tomado em São Paulo.

Afirmar que "A luta do enfermeiro é a luta da enfermagem" é bonito, simpático, mas é falso. A realidade da enfermagem no Brasil é heterogênea; uma área dividida. Reconhecer este fato não é reforçar a divisão; é enfrentar a realidade para possibilitar a sua transformação. $O$ primeiro passo para se tentar mudar uma situação é conhecê-la e não negá-la. Propor a constituição, em separado, de sindicatos de enfermeiros não é reforçar a divisão existente de fato na enfermagem, mas é reconhecer esta divisão; reconhecer que tal divisão tem raízes históricas, fincadas na estrutura social geral, de sociedades estratificadas, na divisão social do trabalho intelectual e manual para, a partir dai, buscar a junção dialética do específico com o genérico. Em outras palavras, mostrar a necessidade, nas atuais circunstâncias, da constituição de sindicatos de enfermeiros não significa demonstrar simultaneamente a impossibilidade de que as várias categorias da enfermagem se unam em torno de suas reivindicações que forem comuns. A classe trabalhadora constitui um conjunto heterogêneo (por isto a expressão é usada freqüentemente no plural), que possui interesses comuns e divergentes. Subestimar o fato de que existem divergências não ajuda a resolver o problema da existência delas. Negar divergências não as elimina. O mecanismo de negação não é o melhor caminho para se mudar uma situação. Não se trata de uma visão sectária e elitista, mas pragmática, realista, de quem tem esperanças em um amanhã em que os direitos humanos fundamentais - à liberdade, à saúde, à educação, ao emprego, à salários justos serão efetivamente respeitados.

SILVA, G.B. da The national conjuncture and the situation of the nurse. Rev. Esc. Enf. USP, São Paulo, 20(3):237-241, 1986.

This article introduces some preliminary considerations about Brazilian nursing and searches the articulation of the social practice with a specific structure and conjuncture. Then it analyses the nursing situation, identifying the heterogeneity which characterizes it, pointing out its contradictions; and finally it discusses the question of unions of nurses.

\section{REFERENCIAS BIBLIOGRAFICAS}

1. Donnangero, M.C.F. Modicina e Sociedade: o medico o sen mercado de trabalho. Săo Paulo, Ploneira, 1975. 174p.

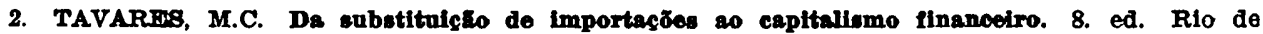
Janeiro, Zahar, 1979. 